Isabela Bonfim ${ }^{1}$

Pedro Gomes ${ }^{1}$

Christiane Haidar ${ }^{1}$

Volnei Garrafa ${ }^{1}$

\title{
BIOÉTICA E CULTIVARES - ESTUDO COMPARATIVO ENTRE O PROJETO DE LEI N. 827/2015 E A LEI DE PROTEÇÃO DE CULTIVARES
}

Bioethics and Cultivars - Comparative study between Bill 827/2015 and the Act on Cultivars Protection

${ }^{1}$ Universidade de Brasília. Brasília/DF, Brasil.

Correspondência: Pedro Gomes. E-mail: pedro.gomes.01@gmail.com

Recebido: 25/01/2017. Aprovado: 07/04/2017. 


\section{RESUMO}

Sob o enfoque da bioética de intervenção, norteada pela Declaração Universal sobre Bioética e Direitos Humanos da Unesco, o presente artigo busca verificar se as alterações propostas à Lei de Proteção de Cultivares (Lei n. 9456/1997) e o conteúdo do Projeto de Lei n. 827/2015, em tramitação na Câmara dos Deputados, garantem a segurança alimentar da população brasileira, incluindo a proteção às formas tradicionais de plantio desenvolvidas pelos pequenos agricultores e pelas comunidades tradicionais. $\mathrm{O}$ texto desenvolve uma análise comparativa entre o projeto de lei ora em tramitação e a própria Lei. Com base na fundamentação teórica da bioética da intervenção, o estudo procura demonstrar que, caso aprovado, o PL n. $827 / 2015$ poderá restringir as práticas tradicionais desenvolvidas pelos pequenos produtores e pelas comunidades tradicionais, que são a base da manutenção da diversidade agrícola e da própria proteção ambiental. Por meio de redefinições na legislação de cultivares, as mudanças propostas aumentam a restrição ao acesso à variabilidade de cultivares, podendo incidir negativamente na segurança alimentar da população, especialmente das comunidades tradicionais e de pequenos grupos populacionais, que constituem a camada mais vulnerável da sociedade brasileira.

\section{Palavras-Chave}

Bioética; Cultivares; Processo Legislativo; Segurança Alimentar.

\section{ABSTRACT}

Under the approach of the bioethics of intervention, guided by Unesco's Universal Declaration on Bioethics and Human Rights, this article seeks to verify whether the proposed amendments to the Law on Protection of Cultivars (Law No. 9456/1997) and the contents of the Bill (PL) no. 827/2015, in course in the Brazilian House of Representatives, guarantee the food security of the Brazilian population, including the protection of traditional forms of farming, developed by small farmers and traditional communities. Based on the theoretical foundations of bioethics of intervention, the study seeks to demonstrate that, if approved, PL 827/2015 may restrict the traditional practices developed by small producers and by traditional communities, which are the basis for maintaining agricultural diversity and even the protection to the environment. By means of redefinitions in cultivar legislation, the changes on the Bill increase the restriction on access to cultivar variability, and may adversely affect the food security of the population, especially the traditional communities and small community groups, which constitute the most vulnerable layers of Brazilian society.

\section{Keywords}

Bioethics; Cultivars; Food Security; Legislative Process. 


\section{Introdução}

Em seu histórico livro Sand County Almanac ${ }^{1}$, publicado em 1949, Aldo Leopold praticamente "inaugurou" o campo de estudo que passou a ser denominado de "ética da terra", quando afirmou que a terra não é uma mercadoria. Essa abordagem baseada no direito à propriedade alimenta e move até hoje os debates sobre as normativas legais com relação ao uso da terra, que incluem discussões morais sobre quem e o que se pode ou não fazer com o espaço ocupado.

A chegada ao século XXI marca um longo processo de transformação social, cuja principal preocupação está centrada na criação de mecanismos que possam equalizar a balança de distribuição de riquezas entre nações e, mais especificamente, entre comunidades. Essa preocupação nasce de outra maior: a própria sobrevivência humana, orientada especialmente pelos princípios de dignidade e equidade ${ }^{2}$.

Um dos grandes dilemas da modernidade é o acesso ao alimento, mais especificamente o acesso a uma alimentação saudável e de qualidade. Esse dilema fez emergir a necessidade de avanço tecnológico ligado ao meio ambiente, a chamada Revolução Verde, que ampliou consideravelmente a produção de alimentos. Porém:

O grande salto de produção agrícola observado a partir dos anos setenta foi sustentado, em grande parte, pelo avanço da fronteira agrícola. Entretanto, quando esse crescimento de área plantada reduziu-se, os níveis de produtividade da terra sustentaram a continuidade do crescimento da produção. No período de 1980 a 1996, a área plantada brasileira diminuiu $2 \%$, mas a produção agrícola elevou-se em mais de $34 \%^{3}$.

Pode-se considerar digno de realce, frente à produtividade, $\mathrm{o}$ aprimoramento de sementes: a cultivar. O desenvolvimento das cultivares é resultado de muitos anos de pesquisa e de aplicação de conhecimento, processos pelos quais o Brasil se destaca no mercado mundial, tanto pelo tamanho de mercado e pelo estoque regulatório adequado, quanto pelo alto grau de investimento e capacitação em tecnologias voltadas aos cultivares.

Isto posto, um grande marco para o estoque regulatório do agronegócio no Brasil foi a aprovação, em 1997, da Lei de Proteção de Cultivares. Ela introduziu a proteção da propriedade intelectual, levando maior desenvolvimento e garantindo pesquisa e desenvolvimento agropecuário, sobretudo no setor de produção

\footnotetext{
${ }^{1}$ LEOPOLD, A. A Sand County Almanac. 1. ed. New York: Oxford University Press, 1949.

2GARRAFA, Volnei; PORTO, Dora. Intervention bioethics: a proposal for peripheral countries in a context of power and injustice. Bioethics, v. 17, n. 5-6, p. 399-416, 2003. Disponível em: <http://onlinelibrary.wiley.com/ doi/10.1111/1467-8519.00356/full. Acesso em: 20 ago. 2016. http://dx.doi.org/10.1111/1467-8519.00356.

${ }^{3}$ ARAÚJO, J.C. A Lei de Proteção de Cultivares: análise de sua formulação e conteúdo. 1. ed. Brasília: Edições Câmara, 2010. p. 19. (Série memória e análise de leis).
} 
de sementes. Porém, decorridos quase 20 anos desde sua aprovação, o parlamento brasileiro retorna à discussão para atualizar e aprimorar esse marco legal.

No Brasil, a Lei de Proteção de Cultivares (Lei n. 9.456/1997) ${ }^{4}$ visa a proteger a propriedade intelectual sobre espécies vegetais com condições genéticas específicas, assim como os direitos dos agricultores detentores desse conhecimento. Nesse sentido, foi proposto na Câmara dos Deputados o Projeto de Lei n. 827, de 2015 (PL n. 827/2015) $)^{5}$, com a justificativa de atualização e aprimoramento para responder às demandas sociais e mercadológicas e que, se aprovado, substituirá a Lei de Proteção de Cultivares vigente.

O presente estudo visa a analisar o PL n. 827/2015, comparando-o criticamente com a Lei de Proteção de Cultivares, com base nos fundamentos teóricos da bioética de intervenção (BI) e norteado pelos princípios da Declaração Universal sobre Bioética e Direitos Humanos da Unesco (DUBDH) ${ }^{6}$, homologada em 2005 em Paris e da qual o Brasil é signatário juntamente com outros 191 países-membros das Nações Unidas. Nesse sentido, a pesquisa pretende estudar se as alterações que constam no projeto de lei em tramitação garantem a segurança alimentar dos brasileiros, especialmente das comunidades tradicionais.

$\mathrm{A} \mathrm{DUBDH}^{7}$ reconhece o respeito aos direitos tanto dos seres humanos quanto do meio ambiente, configurando-se - embora como norma não vinculante - como importante norteador de âmbito internacional capacitado a subsidiar estudos na linha aqui apresentada. A Declaração proporciona uma base de reflexão e discussão ao tema analisado, principalmente no que se refere aos artigos que tratam especificamente do respeito à diversidade cultural e da proteção das gerações futuras e do meio ambiente, bem como da avaliação dos riscos que novas tecnologias podem ocasionar.

Essa proposta epistemológica teórico-aplicada tem sido utilizada no sentido de apresentar a necessidade de empoderar as comunidades na busca de seus legítimos direitos, libertando-a e emancipando-a das amarras que há séculos as vêm mantendo dominadas pelo poder econômico vigente no país desde seu descobrimento $^{8}$. A participação ativa na construção de leis mais justas pode ser incluída no contexto das linhas de leitura crítica propostas pela BI.

\footnotetext{
${ }^{4}$ BRASIL. Lei n. 9456, de 25 de abril de 1997. Institui a Lei de Proteção de Cultivares e dá outras providências. Disponível em: https://www.planalto.gov.br/ccivil_03/Leis/L9456.htm. Acesso em: 15 ago. 2016.

${ }^{5}$ BRASIL. Câmara dos Deputados. Projeto de Lei n. 827, 19 de março de 2015. Altera a Lei n. 9456, de 25 de abril de 1997, que institui a Lei de Proteção de Cultivares e dá outras providências. Disponível em: http:// www.camara.gov.br/proposicoesWeb/prop_mostrarintegra?codteor=1311226\&filename=PL+827/2015. Acesso em: 15 ago. 2016.

${ }^{6}$ ORGANIZAÇÃO DAS NAÇÕES UNIDAS PARA A EDUCAÇÃO, A CIÊNCIA E A CULTURA - UNESCO. Declaração Universal sobre Bioética e Direitos Humanos, de 19 de outubro de 2005. Disponível em: <http://www. bioetica.catedraunesco.unb.br/?page_id=250>. Acesso em: 22 ago. 2016.

${ }^{7}$ GARRAFA, Volnei. Inclusão social no contexto político da Bioética. Revista Brasileira de Bioética, v. 1, n. 2, p. 122-132, 2005. Disponível em: <http://bioetica.org/cuadernos/bibliografia/garrafa.pdf>. ${ }^{8}$ Id. Ibid.
} 


\section{Contextualizando o assunto - bioética, meio ambiente e sociedade}

A Segunda Guerra Mundial fez emergir a necessidade de formulação de cartas de direitos, que procuraram direcionar os avanços científicos, biomédicos e tecnológicos a um norte moralmente ético. É nesse contexto que, a partir do início dos anos 1970, a bioética surgiu nos Estados Unidos da América como uma nova maneira de perceber o mundo, tendo como base uma ética aplicada ${ }^{9}$.

Considerado o criador do neologismo "bioética", o pesquisador estadunidense Van Rensselaer Potter privilegiou, em sua obra pioneira sobre o tema, a preocupação com a interação entre as questões ambientais, a saúde humana e a preservação do ecossistema terrestre ${ }^{10}$. Potter foi originalmente inspirado por Aldo Leopold, em seu texto The Land Ethic, referindo-se a ele, de modo emocionado, como o "primeiro autor da bioética". O texto sobre a "ética da terra" está contido no livro Sand County Almanac ${ }^{11}$, que basicamente defende que a terra não é uma mercadoria passível de posse e que, por essa razão, os seres humanos devem respeitá-la, assim como ela própria o faz.

Desde a promulgação da Constituição de $1988^{12}$ (CF/1988), o Brasil modificou as bases de seu sistema político, trazendo mais agilidade e independência aos três poderes (Legislativo, Executivo e Judiciário) principalmente ao alterar a rotina dos processos decisórios na arena política por meio da reestruturação de sua base constitucional de organização social, política e econômica. Entretanto, apesar desses avanços, autores como Diniz ${ }^{13}$ denunciam a falta de interesse do Estado em prestar contas à população sobre as políticas formuladas e as decisões tomadas.

Nessa linha, Kinzo ${ }^{14}$ fala que, apesar das conquistas trazidas pela redemocratização do Brasil a partir da primeira metade do século XX, ainda existem no país muitos problemas, de natureza tanto política como sociais. A autora sublinha especialmente as questões estruturais que ainda mantêm baixo o padrão de desenvolvimento do país, a enorme desigualdade social e a péssima distribuição de renda.

\footnotetext{
${ }^{9}$ GARRAFA, Volnei. Da bioética de princípios a uma bioética interventiva. Bioética, v. 12, n. 1, p. 125134, 2005. Disponível em: <http://www.revistabioetica.cfm.org.br/index.php/revista_bioetica/article/ view/97/102>. Acesso em: 24 ago. 2016.

${ }^{10}$ POTTER, V.R. Bioética: ponte para o futuro. 1. ed. São Paulo: Ed Loyola; Sociedade Brasileira de Bioética, 2016.

${ }^{11}$ LEOPOLD, A. op. cit.

${ }^{12}$ BRASIL. Constituição da República Federativa do Brasil de 1988. Disponível em:<http://www.planalto.gov. br/ccivil_03/constituicao/constituicaocompilado.htm>. Acesso em: 25 ago. 2016.

${ }^{13}$ DINIZ, Eli.Uma perspectivaanalítica paraa reforma doEstado. Lua Nova,SãoPaulo, n. 45, p. 29-48, 1998. Disponível em: $\quad$ <http://www.scielo.br/scielo.php?script=sci_issuetoc\&pid=0102-644519980003\&nrm=iso\&lng=pt>. Acesso em 20 set. 2016. http://dx.doi.org/10.1590/S0102-64451998000300003.

${ }^{14} \mathrm{KINZO}$, Maria D’Alva. A democratização brasileira: um balanço do processo político desde a transição. Perspectiva, São Paulo, v. 15, n. 4, p. 3-12, 2001. Disponível em: <http://www.scielo.br/scielo. php?script=sci_arttext\&pid=S0102-88392001000400002>. Acesso em: 24 set. 2016. http://dx.doi. org/10.1590/S0102-88392001000400002.
} 
Constatações desse tipo revelam o baixo grau ou mesmo a inexistência de mecanismos efetivos de controle relacionados à prestação de contas do Estado, bem como uma alta concentração decisória e uma baixa permeabilidade pública na máquina estatal, além da ausência de freios institucionais que possam obstaculizar possíveis abusos ${ }^{15}$

Junges $^{16}$, pesquisador brasileiro que trabalha as relações entre a ética e o ambiente, defende que os desafios (bio)éticos da ecologia social e das interfaces entre ambiente e saúde ainda são questões abertas que demandam o devido aprofundamento, reflexão e discussão na agenda latino-americana. Trazendo essa problemática para o Brasil, especialmente no quesito relacionado à segurança alimentar, pode-se perceber que desde o final dos anos 1990 os órgãos governamentais têm buscado construir mecanismos legais que respondam às principais demandas e que se enquadrem nos tratados internacionais dos quais o país é signatário, como o Tratado Internacional sobre Recursos Fitogenéticos para a Alimentação e a Agricultura (TIRFAA) ${ }^{17}$.

Em relação a essa discussão, Junges ${ }^{18}$ ressalta que "o aumento gradativo da população levou a uma maior procura de bens extraídos da natureza e a um consequente incremento da tecnologia", fato que leva a considerar mais enfaticamente as interações do homem com o ambiente, incluindo a produção de alimentos. Nesse contexto, o modelo brasileiro de agricultura segue uma lógica inversa: embora o país seja hoje um dos maiores produtores agrícolas do mundo, boa parte de sua população ainda sofre com a insegurança alimentar ${ }^{19}$, que é entendida como a inacessibilidade a uma alimentação nutritiva e saudável, em quantidade e qualidade adequadas.

Diante da relevância da questão para a segurança alimentar dos brasileiros e para o agronegócio, o governo compreendeu a urgência de proteger os recursos genéticos vegetais, bem como os produtores melhoristas e descritores das espécies vegetais. Deve ser registrada nesse sentido, também, a necessidade de positivar nos códigos legais brasileiros os acordos e tratados internacionais ${ }^{20}$ sobre proteção intelectual dos quais o país é signatário, respeitando o princípio pacta sunt servanda

\footnotetext{
${ }^{15}$ DINIZ, Eli. op. cit.

${ }^{16}$ JUNGES, José Roque. A proteção do meio ambiente na Declaração Universal sobre Bioética e Direitos Humanos. Revista Brasileira de Bioética, v. 2, n. 1, p. 21-38, 2006.

${ }^{17}$ BRASIL. Decreto n. 6476, de 5 de junho de 2008. Promulga o Tratado Internacional sobre Recursos Fitogenéticos para a Alimentação e a Agricultura. Disponível em: <https://www.planalto.gov.br/ccivil_03/_ ato2007-2010/2008/decreto/d6476.htm>. Acesso em: 2 set. 2016.

18JUNGES, José Roque. op. cit.

${ }^{19}$ SARAIVA, Alessandra. 7,2 milhões de pessoas passam fome no Brasil, mostra IBGE. Valor Econômico, 18 dez. 2014. Disponível em: <http://www.valor.com.br/brasil/3829144/72-milhoes-de-pessoas-passamfome-no-brasil-mostra-ibge>. Acesso em: 5 set. 2016.

${ }^{20}$ Alguns destes tratados são: União para a Proteção das Obtenções Vegetais (UPOV); Convenção sobre Biodiversidade (CDB) e o Tratado Internacional sobre Recursos Fitogenéticos para a Alimentação e a Agricultura (TIRFFA).
} 
(os pactos devem ser cumpridos) do Direito Internacional ${ }^{21}$. Foi neste contexto que surgiu a Lei de Proteção de Cultivares.

Para melhor compreensão do tema aqui abordado, é indispensável esclarecer o significado da palavra "cultivar", que fundiu partes dos vocábulos cultivated variety, do idioma inglês. Para efeitos do presente estudo, então, será adotado o seguinte conceito para o termo:

Uma cultivar é resultado de melhoramento em uma variedade de planta que a torne diferente das demais em sua coloração, porte, resistência a doenças. A nova característica deve ser igual em todas as plantas da mesma cultivar, mantida ao longo das gerações. Embora a nova cultivar seja diferente das que a originaram, não pode ser considerada geneticamente modificada; o que ocorre é uma nova combinação do seu próprio material genético ${ }^{22}$.

À vista disso, a tramitação de um projeto de lei que pretende alterar o arcabouço regulatório brasileiro em relação à proteção de cultivares merece especial atenção analítica pelo impacto social, econômico e político que pode acarretar em diferentes instâncias da realidade futura do país. O propósito deste estudo, portanto, é analisar tal processo legislativo, tomando a BI e a DUBDH como referências teóricas, na busca do estabelecimento de pontos críticos que possam existir no PL $\mathrm{n}$. $827 / 2015$, atualmente em discussão no Congresso Nacional.

\section{Cultivares: origem e desenvolvimento}

A palavra agricultura vem do latim agricultūra, composta por ager (campo, território) e cultūra (cultivo), no sentido estrito de cultivo do solo. Acredita-se que, por volta de 10 mil anos atrás, começaram a ser desenvolvidos os primeiros cultivos de plantas, o que se intitulou revolução agrícola neolítica ${ }^{23}$. Durante muito tempo, os conhecimentos sobre o cultivo da terra foram passados de geração para geração, a partir dos saberes sobre a natureza e da própria biodiversidade existente.

Conforme a civilização foi se concentrando em aglomerados que formariam as futuras cidades, houve a necessidade de aperfeiçoar a produção das espécies alimentícias. Dessa forma, conforme fosse detectada alguma utilidade em uma

\footnotetext{
${ }^{21}$ MINARÉ, Reginaldo. TIRFAA e o acesso ao patrimônio genético e repartição de benefícios. Audiência Pública da Câmara dos Deputados, 2013, Brasília. Disponível em: <http://www2.camara.leg.br/atividadelegislativa/comissoes/comissoes-permanentes/capadr/audiencias-publicas/audiencias-publicas-2013/ audiencia-publica-03-de-abril-de-2013-cna>. Acesso em: 20 ago. 2016.

${ }^{22}$ BRASIL. Ministério da Agricultura, Pecuária e Abastecimento. Proteção de Cultivares. Disponível em: <http://www.agricultura.gov.br/vegetal/registros-autorizacoes/protecao-cultivares/cultivares-protegidas>. Acesso em: 23 ago. 2016.

${ }^{23}$ JUNGES, José Roque. op. cit.
} 
planta, esta passava imediatamente a ser cultivada ${ }^{24}$, tentando-se assim descobrir e proteger as melhores características que o vegetal apresentava (resistência às pragas e intempéries, menor tempo para colheita, maior capacidade nutricional), dentro de sua variabilidade genética. Para isso é utilizado o chamado melhoramento genético, que engloba todas as técnicas, métodos, estratégias ou recursos empregados para que algum progresso possa ser incorporado a uma espécie vegetal.

É importante ressaltar que a seleção artificial realizada com o melhoramento genético pode descartar uma parte dos genótipos que não são interessantes, o que resulta em redução na variabilidade genética e, consequentemente, em ameaça ao meio ambiente. Há relatos na área agrícola que evidenciam drásticas alterações relacionadas à falta de variabilidade nos campos de produção, fazendo com que as plantações tornem-se uniformes - o que causa vulnerabilidade genética e expõe as plantações a situações adversas como pragas e outros tipos de efeitos deletérios ${ }^{25}$. Por esse motivo, deve-se dar especial atenção à conservação das espécies nativas, denominadas crioulas.

Conforme conceitua o artigo $2^{\circ}$, inciso XV, da Lei n. 10.711/2003: “Cultivar: a variedade de qualquer gênero ou espécie vegetal superior que seja claramente distinguível de outras cultivares conhecidas [...] que seja homogênea e estável quanto aos descritores através de gerações sucessivas" ${ }^{26}$. E a lei também diferencia o cultivar tradicional, em seu inciso XVI:

[...] cultivar local, tradicional ou crioula: variedade desenvolvida, adaptada ou produzida por agricultores familiares, assentados da reforma agrária ou indígenas, com características fenotípicas bem determinadas e reconhecidas pelas respectivas comunidades e que, a critério do MAPA, considerados também os descritores socioculturais e ambientais, não se caracterizem como substancialmente semelhantes às cultivares comerciais $[\ldots]^{27}$;

A importância desse tipo de cultivo é cada vez maior, pois cultivar plantas melhoradas geneticamente é a proposta das cultivares para suprir as mais diversas necessidades, nos mais variados âmbitos, como os de alimentação, agricultura, usos químicos, farmacêuticos e de biocombustíveis ${ }^{28}$. Porém o desenvolvimento

\footnotetext{
${ }^{24}$ CARSON, R. Primavera silenciosa. 1. ed. São Paulo: Ed. Gaia, 2012.

${ }^{25}$ CARLINI-GARCIA, Luciana; PINTO, Luciana Rossini; LANDELL, Marcos Guimarães. Importância da manutenção de variabilidade genética para os produtores rurais. Secretaria de Agricultura de São Paulo, jul./dez. 2013. Disponível em: <http://www.aptaregional.sp.gov.br/acesse-os-artigos-pesquisa-etecnologia/edicao-2013/julho-dezembro-1/1444-importancia-da-manutencao-de-variabilidade-geneticapara-os-produtores-rurais/file.html>. Acesso em: 15 set. 2016.

${ }^{26}$ BRASIL. Lei n. 10711, de 5 de agosto de 2003. Dispõe sobre o Sistema Nacional de Sementes e Mudas e dá outras providências. Disponível em: <http://www.planalto.gov.br/ccivil_03/leis/2003/L10.711.htm>. Acesso em: 20 ago. 2016.

${ }^{27}$ Id. Ibid.

${ }^{28}$ SEVERINO, Mariana Rocha Souza; LIMA, Thaizi Leal Mesquita; LIMA, Gabriel Maciel; DANTAS, Tomas Kefas
} 
dessas variações pela agroindústria passou a desconsiderar o papel dos pequenos agricultores em suas comunidades, considerando-os apenas como usuários finais do melhoramento ${ }^{29}$.

Para que a nova cultivar seja protegida e conservada, são necessários dois passos: o registro e a solicitação para a proteção intelectual; e o depósito de seus caracteres genéticos em um repositório, para consulta e futuros estudos. Após a obtenção da variedade vegetal de uma espécie (cultivar) pelo melhorista, ela deve ser registrada no Serviço Nacional de Proteção de Cultivar (SNPC), órgão vinculado ao Ministério da Agricultura, Pecuária e Abastecimento (MAPA) responsável pela concessão dos certificados de proteção.

Apesar de existirem duas formas de proteção das variedades vegetais (patentes utilizadas nos Estados Unidos da América; ou sui generis, presentes na União Europeia), o Brasil aderiu, em 1999, à Convenção da União para a Proteção das Obtenções Vegetais (UPOV, Ata de 1978), optando pela aplicação de um sistema de proteção sui generis, cujo conteúdo apresenta objeto, limitações e requisitos, tais como a novidade, a distinguibilidade, a homogeneidade e a estabilidade ${ }^{30}$.

O passo seguinte para a proteção da cultivar obtida é a conservação do material genético, que costuma ocorrer com o auxílio dos bancos de germoplasma, que são repositórios de material genético e da variabilidade genética, parcial ou total, de determinada espécie vegetal, sendo esta a fonte genética utilizada pelo melhorista para desenvolver novas cultivares. Dessa forma, o principal objetivo da manutenção desses bancos é manter a variabilidade e evitar a erosão genética, disponibilizando material para os melhoristas.

Outra forma de conservação do material genético vegetal das espécies crioulas ou autóctones é realizada pelos agricultores familiares, que costumam guardar sementes para os próximos plantios, além de trocá-las entre si, observando a característica de cada cultivar para determinada época, condições climáticas e cultivo concomitante com outras culturas ${ }^{31}$. Ambas as formas de conservação das

de Souza. A importância socioeconômica das cultivares para o desenvolvimento dos biocombustíveis no Brasil. In: SIMPÓSIO INTERNACIONAL DE INOVAÇÃO TECNOLÓGICA, v. 2, n. 1, p. 77-84, set. 2014. Disponível em: $\quad$ <http://www.portalmites.com.br/conferences/index.php/ISTI/isti2014/paper/download/25/12>. Acesso em: 20 ago. 2016. http://dx.doi.org/10.7198/S2318-3403201400020010.

${ }^{29}$ SANTILLI, Juliana Ferraz da Rocha. Agrobiodiversidade e direitos dos agricultores. 2009. Tese (Doutorado) - Faculdade de Direito, Pontifícia Universidade Católica do Paraná, 2009.

${ }^{30}$ LEITE, Débora Silva; MUNHOZ, Letícia Leite. Biotecnologia e melhoramento das variedades vegetais. Veredas do Direito: direito ambiental e desenvolvimento sustentável, Belo Horizonte, v. 10, n. 19, p. 2344, jan./jun. 2013. Disponível em <http://www.domhelder.edu.br/revista/index.php/veredas/article/ view/301/337>. Acesso em: 11 ago. 2016.

${ }^{31}$ PIPOLO, Antônio Eduardo; ARIAS, Carlos Alberto Arrabal; CARNEIRO, Geraldo Estevam de Souza; TOLEDO, José Francisco Ferraz. Desenvolvimento de Germoplasma e Cultivares de Soja. Circular Técnica n. 52. Empresa Brasileira de Pesquisa Agropecuária, set. 2007. Disponível em: <https://www.infoteca.cnptia. embrapa.br/handle/doc/470314>. Acesso em: 25 ago. 2016. 
variedades vegetais protegem a biodiversidade florística e a riqueza nutricional, garantindo insumos que podem evitar a insegurança alimentar.

Segundo a Lei n. 11.346/2006, que cria o Sistema Nacional de Segurança Alimentar e Nutricional (Sisan), em seu artigo $3^{\circ}$, "segurança alimentar e nutricional" consiste $\mathrm{na}^{32}$ :

realização do direito de todos ao acesso regular e permanente a alimentos de qualidade, em quantidade suficiente, sem comprometer o acesso a outras necessidades essenciais, tendo como base práticas alimentares promotoras de saúde que respeitem a diversidade cultural e que sejam ambiental, cultural, econômica e socialmente sustentáveis ${ }^{33}$.

A despeito do mencionado instrumento legal, Arantes $^{34}$ alerta que as condições de segurança alimentar só são construídas a partir da vontade política e da ação dos governos. Essa segurança alimentar não é uma conquista definitiva, estática, pois apresenta desafios cada vez maiores, como: aumento gradual da produção global de alimento; otimização do acesso a tecnologias e biotecnologias agrícolas que permitam aumento de produtividade entre todos os agricultores; redução do desperdício; conservação dos recursos naturais; e melhora dos hábitos alimentares ${ }^{35}$. Além disso, há a questão do êxodo rural, já que é necessário produzir mais com menos pessoas vivendo no campo $^{36}$, fato que demanda o incremento cada vez maior da produção de insumos vegetais utilizando as mais variadas técnicas, inclusive a do melhoramento genético.

\section{0 problema legislativo}

No Brasil existem especificidades quanto à feitura e aprovação das leis. Tal visão pode ser compartilhada com Lemos em seu estudo sobre a produção legislativa de origem parlamentar nos temas de saúde e educação no governo de transição da Constituinte e no primeiro governo democrático (de 1988 até 1994). A autora, igualmente a Amorim Neto e Santos, constata que existe preponderância dos projetos

32SARAIVA, Alessandra. op. cit.

${ }^{33}$ BRASIL. Lei n. 11.346, de 15 de setembro de 2006. Disponível em: <https://www.planalto.gov.br/ ccivil_03/_ato2004-2006/2006/lei/I11346.htm>. Acesso em: 2 set. 2016.

${ }^{34}$ ARANTES, Olívia Márcia Nagy. A bioética e a segurança alimentar: alimentos geneticamente modificados. Revista Brasileira de Pesquisa em Saúde, v. 14, n. 3, p. 14-20, 2012. Disponível em: <http://periodicos. ufes.br/RBPS/article/viewFile/4598/3567>. Acesso em: 20 de set. 2016. http://dx.doi.org/10.21722/ rbps.v14i3.4598.

${ }^{35}$ Id. Ibid. p. 15-16.

${ }^{36}$ VALOIS, Afonso Celso Candeira. Biotecnologia, biodiversidade e propriedade intelectual. Cadernos de Ciência e Tecnologia, Brasília, v. 15, esp. p. 21-31, 1998. Disponível em: <http://www.egov.ufsc.br/portal/ sites/default/files/anexos/27615-27625-1-PB.pdf>. 
socialmente benéficos e de cunho regulatório em função de outras temáticas dos projetos de lei $i^{37},{ }^{38}$.

Os dois últimos autores acima, complementarmente ao estudo de Lemos, analisaram as distribuições de temas entre as proposições apresentadas por parlamentares: eles defendem que existe uma diferenciação entre a agenda proposta pelo Poder Executivo e aquelas propostas pelos parlamentares. O primeiro tem prioridade de legislar sobre projetos mais generalistas e abstratos, com menor impacto na vida dos indivíduos, enquanto os últimos legislam sobre temáticas de abrangência nacional, socialmente benéficos e impactantes. Isso justificaria, no caso do PL $\mathrm{n}$. $827 / 2015$, o fato de ser uma proposta de autoria parlamentar.

Passados quase 20 anos, a Lei de Proteção de Cultivares necessita de ajustes para se adequar às novas demandas do mercado e da sociedade, incluindo também, e de modo essencial, a proteção e preservação das práticas tradicionais de cultivo. Além disso, é necessário que passe a incluir em seu conteúdo a defesa das comunidades tradicionais que detêm esse conhecimento, além de garantir a segurança alimentar nacional dessas populações e da própria sociedade como um todo, principalmente das classes menos favorecidas social e economicamente.

De acordo com dados da Empresa Brasileira de Pesquisa Agropecuária (Embrapa), o Brasil tornou-se um dos líderes mundiais no mercado de produtos agrícolas nas últimas duas décadas, fazendo com que o agronegócio nacional ultrapasse o patamar de $20 \%$ do Produto Interno Bruto (PIB) nacional ${ }^{39}$. Contudo, paralelamente ao percentual baseado nas exportações, é indispensável registrar que a produção agrícola derivada de pequenos produtores é a responsável pela base do abastecimento interno da alimentação dos brasileiros. Ademais, juntamente aos recursos genéticos relacionados com plantas, animais e microrganismos, a propriedade intelectual e a biotecnologia têm um primordial papel no sentido de contribuir firmemente para mitigar a pobreza, conservar e usar os recursos naturais bióticos e abióticos e possibilitar a segurança alimentar da população, sendo ainda um significativo suporte para assegurar a proteção ambiental e a sustentabilidade da agricultura ${ }^{40}$.

\footnotetext{
${ }^{37}$ LEMOS, Leany Barreiro de S. O Congresso brasileiro e a distribuição de benefícios sociais no período 19881994: uma análise distributivista. DADOS - Revista de Ciências Sociais, v. 44, n. 3, p. 561-605, 2001. Disponivel em: <http://www.scielo.br/pdf/dados/v44n3/a04v44n3.pdf>. Acesso em: 11 ago. 2016. http://dx.doi.org/10.1590/S0011-52582001000300004.

${ }^{38}$ AMORIM NETO, Otávio; SANTOS, Fabiano. O segredo ineficiente revisto: o que propõem e o que aprovam os deputados brasileiros. DADOS -- Revista de Ciências Sociais, Brasil, v. 46, n. 4, p. 661-698, 2003. Disponível em: <http://www.scielo.br/scielo.php?pid=S0011-52582003000400002\&script=sci_abstract\&tlng=es>. Acesso em: 28 set. 2016. http://dx.doi.org/10.1590/S0011-52582003000400002.

${ }^{39}$ EMBRAPA. EMPRESA BRASILEIRA DE PESQUISA AGROPECUÁRIA. A variabilidade genética como fator fundamental aos programas de melhoramento vegetal. Documentos online 29, 2002. Disponível em: <www.cnpt.embrapa.br/biblio/p_do29_5.htm>. Acesso em: 21 set. 2016.

${ }^{40}$ VALOIS, Afonso Celso Candeira. op. cit.
} 
Com tema de tamanha importância para o país, a legislação precisou passar por transformações, para proteger tanto a agricultura em si como aqueles que são responsáveis por ela, sejam eles pequenos, médios ou grandes agricultores. Foi nesse contexto que, em 1997, se deu a promulgação da Lei de Proteção de Cultivares, que garantiu direitos relativos à propriedade intelectual das cultivares, principalmente às novos cultivares e às cultivares essencialmente derivadas.

O ajuste pretendido na Lei de Cultivares se estabelece por intercessão do PL n. 827/2015, que traz alterações na legislação vigente, as quais, contudo, podem afetar diretamente os produtores de pequena escala, em especial os pequenos agricultores $^{41}$, entre outros segmentos sociais vulneráveis, como os quilombolas e indígenas.

A lei atual prevê para qualquer agricultor o direito de reservar e plantar sementes para uso próprio, em estabelecimentos de cuja posse seja titular (chamado de privilégio do agricultor) e também o direito de usar e vender o produto obtido com o plantio como alimento ou matéria-prima. Mas, especificamente para o pequeno produtor rural, a lei em vigência reserva o direito de multiplicação de sementes para casos de doação ou troca com outros agricultores rurais no âmbito de programas de financiamento. Sobre o projeto original do qual nasceu a Lei de Proteção de Cultivares, a Promotora de Justiça Juliana Santilli observa:

Durante a tramitação do projeto de lei no Congresso Nacional, essa foi uma das questões mais polêmicas, pois as organizações da sociedade civil sustentaram arduamente que os pequenos agricultores deveriam ter um tratamento diferenciado não só para a multiplicação de sementes para doação ou troca, mas também para a venda. A venda de sementes acabou, entretanto, sendo excluída do projeto de lei aprovado, e a necessidade de autorização do obtentor (e de pagamento de royalties) para a produção comercial de sementes de variedades protegidas tem trazido enormes dificuldades para que os pequenos agricultores possam produzir as suas próprias sementes e vendê-las a outros pequenos agricultores em mercados locais ${ }^{42}$.

No entanto, inversamente, o PL n. 827/2015 dá mais garantias aos detentores dos direitos sobre as cultivares, ao prever o pagamento de royalties para salvamento de sementes e a proibição de doação de sementes, além de restringir mais ainda

\footnotetext{
${ }^{41} \mathrm{Art}$. 10, § 30: “Considera-se pequeno produtor rural, para fins do disposto no inciso IV do caput, aquele que, simultaneamente, atenda os seguintes requisitos: I - explore parcela de terra na condição de proprietário, posseiro, arrendatário ou parceiro; II - mantenha até dois empregados permanentes, sendo admitido ainda o recurso eventual à ajuda de terceiros, quando a natureza sazonal da atividade agropecuária o exigir; III não detenha, a qualquer título, área superior a quatro módulos fiscais, quantificados segundo a legislação em vigor; IV - tenha, no mínimo, oitenta por cento de sua renda bruta anual proveniente da exploração agropecuária ou extrativa; e V - resida na propriedade ou em aglomerado urbano ou rural próximo." BRASIL. Lei n. 9.456, de 25 de abril de 1997, cit.

${ }^{42}$ SANTILLI, Juliana Ferraz da Rocha op. cit.
} 
os grupos e comunidades não atingidos pelas restrições da lei. Por conseguinte, as mudanças preteridas pelo projeto de lei suscitam questionamentos relevantes sobre os objetivos: se priorizam as culturas tradicionais e os povos vulneráveis; se garantem a subsistência de suas culturas com segurança alimentar; e se mantêm a proteção de seus cultivares.

$\mathrm{Na}$ atual lei, o artigo $8^{\circ}$ decide que a proteção da cultivar recairá sobre o material de reprodução ou de multiplicação vegetativa da planta inteira, mas a alteração proposta no PL n. 827/2015 define que a proteção da cultivar se dará sobre qualquer forma de propagação da planta inteira. Seu artigo $9^{\circ}$ assegura ao titular da cultivar o direito à produção de sementes ou de qualquer forma de multiplicação comercial da cultivar e sua comercialização no território brasileiro. Além disso, veta, durante o prazo de proteção, a utilização das sementes para uso próprio sem a autorização expressa do titular do direito, além de sua comercialização, seu acondicionamento e armazenamento para fins comerciais, de material de propagação da cultivar protegida, independentemente da utilização de sua correta denominação.

O artigo 10 diz respeito ao que não fere o direito de proteção sobre cultivar protegida. Na legislação atual, é permitido reservar as sementes para uso próprio ou em estabelecimento de terceiros e usar ou vender como alimento ou matéria-prima o produto obtido de seu plantio, exceto para fins reprodutivos. Com relação à guarda e conservação das sementes para uso próprio, devem ser atendidas condições em que o agricultor tenha adquirido material de reprodução certificado: utilização no prazo limite de um ano e em no máximo $50 \%$ de sua área a ser plantada com a cultivar protegida; pagamento dos royalties ao obtentor da cultivar, independentemente de autorização prévia; e pagamento dos royalties ao obtentor de tecnologia, independentemente de autorização prévia.

O PL n. 827/2015 traz o conceito de agricultor familiar previsto na Lei n. 11.326, de 24 de julho de 2006, que estabelece as diretrizes para a formulação da Política Nacional da Agricultura Familiar e Empreendimentos Familiares Rurais ${ }^{43}$. Além dos agricultores familiares, inclui também os integrantes de povos indígenas ou de comunidades tradicionais em relação à reserva e à planta material de propagação para uso próprio. Admite a comercialização dessa produção, desde que não seja para fins de propagação da cultivar, e também a multiplicação material de propagação para uso próprio ou para doação ou troca com outros integrantes dos grupos. E acrescenta um parágrafo que estabelece que não se aplicará o uso próprio às flores e plantas ornamentais.

A lei das cultivares dispõe de um capítulo sobre as sanções, o Capítulo IV. A proposta do projeto de lei é alterar esse capítulo para tutela judicial, que será a

\footnotetext{
${ }^{43}$ Brasil. Lei n. 11. 326, de 24 de julho de 2006. Disponível em: <http://www.planalto.gov.br/ccivil_03/_ ato2004-2006/2006/lei/l11326.htm>. Acesso em: 14 jun. 2016.
} 
prescrição da pretensão de reparar danos, prescrevendo em cinco anos a pretensão de reparação de dano causado por violação aos direitos de proteção de cultivares. Estabelece, ainda, pena de detenção, de três meses a um ano, ou multa, a quem: expuser, ofertar, vender, consignar, beneficiar, embalar, reembalar, ceder a qualquer título, importar e exportar cultivar protegida ou suas partes, com denominação correta ou não; e reproduzir ou multiplicar, com finalidade de comercialização, material propagativo ou produto de colheita de cultivar protegida, com violação aos direitos do seu titular. As ações penais e as diligências preliminares de busca e apreensão, nos crimes contra a cultivar protegida, também irão ser reguladas pelo disposto no Código Penal.

\section{A discussão sobre Bioética e cultivares no Brasil}

Em seu primeiro postulado, o PL n. 827.2015 visa a alterar a Lei de Proteção de Cultivares. O autor da proposta justifica a alteração na lei pela ampliação dos direitos dos obtentores vegetais sobre o material de multiplicação da cultivar protegida. Também justifica:

Tendo em vista a necessidade de melhoria desses pontos apresentamos o referido projeto com a finalidade de contemplar a justa remuneração pelo indispensável trabalho de pesquisa e desenvolvimento realizado pelos melhoradores e, ao mesmo tempo, preservar o direito de uso de sementes salvas por pequenos, médios e grandes produtores rurais na medida de suas especificidades ${ }^{44}$.

O PL n. 827/2015 altera quatro artigos da Lei de Proteção de Cultivares: o artigo $8^{\circ}$, que trata sobre a proteção da cultivar; o artigo $9^{\circ}$, que trata sobre o direito de uso da cultivar pelo titular; o artigo 10, que dispõe sobre as autorizações de uso da cultivar; e o artigo 37, que trata das sanções e que está sendo ampliado de um artigo para um capítulo individual.

E é justamente nos artigos $9^{\circ}$ e 10 que se insere a questão da segurança alimentar, seja com relação às questões pertinentes à restrição de guarda e à restrição de uso, seja com relação a quem pode ou não guardar e utilizar as sementes e o fruto de sua produção. Também se inserem aqui, por um lado, a questão do aumento da proteção a cultivares desenvolvidos e, por outro, a questão das sementes crioulas e seu uso pelas comunidades tradicionais, as quais têm resistido à substituição pelo uso de sementes modificadas:

Nos últimos anos, tem-se dado atenção especial às comunidades agrícolas tradicionais não só como mantenedoras da diversidade biológica natural, em função de suas práticas agrícolas de baixo impacto, mas também como guardiãs da

\footnotetext{
${ }^{44}$ BRASIL. Câmara dos Deputados. Projeto de Lei n. 827, 19 de março de 2015, cit.
} 
variabilidade e biodiversidade das plantas cultivadas e do conhecimento associado a toda essa riqueza ${ }^{45}$.

Sob um enfoque da BI, Nascimento e Garrafa propõem um modelo de solidariedade crítica ${ }^{46}$ como caminho para a busca de um estado de bem-estar social, principalmente no que se refere aos indivíduos e grupos mais vulneráveis na sociedade:

Pensamos em uma solidariedade crítica, exatamente para evitar a armadilha colonial de sermos solidários em causa própria, no sentido de beneficiar apenas nossos próprios interesses. A crítica aqui é também uma autocrítica, na medida em que nossos posicionamentos e interesses também estarão em questão. A construção da solidariedade crítica poderá se efetivar em mudanças político-sociais [...] por meio da ação concreta de grupos organizados e preocupados com radicais transformações políticas no sentido da luta pela inserção crescente do maior número possível de pessoas nos processos de tomada de decisão, ao mesmo tempo em que se problematizam as maneiras hegemônicas de decidir politicamente ${ }^{47}$.

A solidariedade crítica, portanto, é uma proposta de ação interventiva, comprometida com a busca por políticas sociais justas, democráticas e equitativas, capazes de promover resultados inclusivos nos âmbitos individual e coletivo. Os sujeitos desta solidariedade, devidamente empoderados, têm a possibilidade de se perceberem como indivíduos aptos a exercer direitos políticos de modo a defenderem, em última instância, sua autonomia e liberdade na luta pela igualdade. "A solidariedade crítica é um valor ético [...] valor central que motiva a auto-organização social [...] constitui um espaço singular para o exercício da cidadania nos marcos de uma democracia participativa"48. Essa prática orgânica é que guia o entendimento próprio de cada indivíduo e de seu papel na sociedade civil. Como apontam os próprios autores acima referidos, a democracia brasileira exige que os indivíduos/cidadãos participem de forma radical e efetiva da condução das atividades públicas e, mais precisamente, das

\footnotetext{
${ }^{45}$ PELWING, Andrea Becker; FRANK, Lúcia Brandão; BARROS, Ingrid Bergman. Sementes crioulas: o estado da arte no Rio Grande do Sul. Revista de Economia e Sociologia Rural, v. 46, n. 2, p. 395, 2008. Disponível em: <http://www.scielo.br/pdf/resr/v46n2/v46n2a05.pdf>. Acesso em: 17 ago. 2016. http://dx.doi. org/10.1590/S0103-20032008000200005.

${ }^{46}$ NASCIMENTO, Wanderson Flor; GARRAFA, Volnei. Por uma vida não colonizada: diálogo entre bioética de intervenção e colonialidade. Saúde e Sociedade, São Paulo, v. 20, n. 2, p. 287-299, 2011. Disponível em: <http://www.revistas.usp.br/sausoc/article/download/29791/31673>. Acesso em: 5 nov. 2016. http:// dx.doi.org/10.1590/S0104-12902011000200003.

${ }^{47}$ Ibid. Id., p. 297.

${ }^{48}$ SELLI, Lucilda; GARRAFA, Volnei. Solidariedade crítica e voluntariado orgânico: outra possibilidade de intervenção societária. História, Ciências e Saúde - Manguinhos, v. 13, n. 2, p. 239-251, abr./jun. 2006. Disponivel em <http://www.scielo.br/scielo.php?script=sci_arttext\&pid=S0104-59702006000200003>. Acesso em: 5 nov. 2016. http://dx.doi.org/10.1590/S0104-59702006000200003.
} 
tomadas de decisão, de modo a formarem um grupo de pressão legítimo para influenciar decisões políticas que impactam suas vidas e a própria democracia.

Assim, a BI apresenta-se como um instrumento para pensar alternativas ao desenvolvimento social na América Latina. Em sua defesa teórica, a BI demonstra uma preocupação pontual com o desenvolvimento da tecnologia, sobretudo pelo fato de esta dividir o mundo em dois grupos, a saber: um grupo pequeno, mas "central", de detentores do poder e das tecnologias; e um grupo grande, de países e indivíduos "periféricos", que se submetem aos que detêm o poder.

Garrafa e Porto defendem que, assim como a distribuição do poder, a distribuição de saúde e de recursos para consumo também é inversamente proporcional. Ou seja, o menor grupo de pessoas detém a maior parte do acesso à saúde e aos recursos responsáveis por proporcionar uma vida baseada na máxima dignidade. Nesse sentido, os autores abordam a questão do acesso à segurança alimentar:

A produção de alimentos no mundo atual, por exemplo, suplanta em centenas de milhões de toneladas as necessidades nutricionais dos seis bilhões de habitantes do planeta. No entanto, devido a problemas na distribuição, o contingente de pessoas que ainda morrem de fome ou de suas consequências é incalculável ${ }^{49}$.

Por conseguinte, fica claro que a bioética também está atenta em defender a proteção social, inclusive quanto aos direitos de propriedade intelectual, sobretudo quando envolve produção de larga escala que ponha em risco a manutenção e proteção do conhecimento tradicional ${ }^{50}$. "Portanto, não se pode permitir o esquecimento da redefinição da identidade daquele povo diante da sua luta como agente de suas próprias vidas, com direito ao convívio com respeito à diversidade, dignidade humana e cidadania"s1.

A importância do tema também está presente na DUBDHU, que, em seu artigo 12, dispõe sobre a importância do respeito à diversidade cultural e do pluralismo, como formas de respeito efetivo à dignidade e aos direitos humanos. Também, o artigo 20 trata da necessidade de uma avaliação adequada dos riscos associados às tecnologias, para que estas preservem o meio ambiente e não lhe causem dano.

\footnotetext{
49"Food production in the current world, for instance, supplants in hundred millions of ton the nutritional needs of the 6 billion inhabitants of the planet. However, due to problems in distribution, the contingent of people that still die hunger or of its consequences is uncountable". GARRAFA, Volnei; PORTO, Dora. op. cit., p. 406.

${ }^{50}$ SANTOS, Denise Tatiane Girardon. A bioética como mecanismo de proteção dos conhecimentos tradicionais dos povos indígenas e de afirmação dos direitos humanos. Revista Direito em Debate - Revista do Departamento de Ciências Jurídicas e Sociais da Unijuí, v. 23, n. 42, p. 3-26, 2014. Disponível em: <https:// www.revistas.unijui.edu.br/index.php/revistadireitoemdebate/article/view/2984/3504>. Acesso em: 5 set. 2016. http://dx.doi.org/10.21527/2176-6622.2014.42.3-26.

${ }^{51}$ VIEIRA, Ana Beatriz Duarte; MONTEIRO, Pedro Sadi. Comunidade quilombola: análise do problema persistente do acesso à saúde, sob o enfoque da Bioética de Intervenção. Revista Saúde em Debate, Rio de Janeiro, v. 37, n. 99, p. 611, 2013. Disponível em: <http://www.scielo.br/pdf/sdeb/v37n99/a08v37n99. pdf>. Acesso em: 17 ago. 2016. http://dx.doi.org/10.1590/S0103-11042013000400008.
} 
Complementarmente, os artigos 16 e 17 da DUBDH abordam a necessidade de proteção para as gerações futuras e a proteção do meio ambiente e da biodiversidade, respectivamente. Seguindo essa linha, faz-se necessário integrar seus postulados na construção das políticas públicas, porquanto se apresentam como ferramenta de relevância global. Igualmente, trata-se de um problema de mérito global, principalmente da América Latina, que, concomitantemente aos processos de industrialização e urbanização, vem paulatinamente perdendo sua riqueza cultural e material.

Sob o enfoque crítico da BI, a atual redação do PL n. 827/2015 pode levar os pequenos produtores e as comunidades tradicionais a uma situação de insegurança alimentar, na medida em que estes dependem da conservação das diversidades biológica e genética na agricultura. Nesse sentido, vale registrar o seguinte:

Só no Brasil o Programa Nacional de Fortalecimento da Agricultura Familiar (Pronaf), do Ministério do Desenvolvimento Agrário, estima que a categoria "agricultores tradicionais" represente em torno de $15 \%$ da população agrícola, e a diversidade agrícola constitui a base de sua sobrevivência e da estabilidade de seus sistemas agrícolas. A redução da diversidade agrícola, entretanto, compromete a sustentabilidade de todos os sistemas agrícolas, e não só da agricultura tradicional e familiar, ainda que os impactos sejam distintos ${ }^{52}$.

Caso seja aprovado, o PL n. 827/2015 poderá restringir a prática tradicional da troca de sementes entre os pequenos produtores e nas comunidades tradicionais, que é a base da troca de conhecimentos agrícolas e ampliação da diversidade agrícola, fator fundamental na prática nutricional, e por consequência, na segurança alimentar dessas comunidades.

Também, a definição que o projeto quer trazer para o "pequeno produtor", restringindo sua caracterização a uma área específica de modelos fiscais, dificulta a adesão de comunidades tradicionais, como o caso das tribos amazônicas. O que caracteriza as comunidades tradicionais não é a área plantada, mas sim as formas de cultura que praticam ${ }^{53}$.

\section{Considerações finais}

A BI apresenta-se como ferramenta útil às discussões legislativas de matérias que coloquem em voga direitos básicos a uma vida digna, saudável e com garantias formais de invulnerabilidade. Cabe ressaltar que ainda está incipiente a atuação bioética no Parlamento brasileiro, embora a realidade social e a realidade regulatória

\footnotetext{
${ }^{52}$ SANTILLI, Juliana Ferraz da Rocha. Agrobiodiversidade e direito dos agricultores. 1. ed. São Paulo: Ed. Peirópoles, 2009. p. 2.

${ }^{53}$ Id. Ibid.
} 
careçam de análises sociais plurais, que considerem as nuances culturais, diferenças e particularidades.

O grande interesse em atualizar a legislação ambiental, aumentando a restrição ao acesso à variabilidade de cultivares por meio de redefinições na legislação de cultivares propostas pelo PL n. 827/2015, pode restringir a segurança alimentar das comunidades tradicionais e de pequenos grupos populacionais, que se encontram na camada mais frágil da população brasileira.

O Brasil enfrenta desafios consideráveis para atualizar seu arcabouço regulatório de modo a trazer, por um lado, segurança jurídica e um mercado saudável e, por outro, a segurança de sua população, sobretudo no que se refere aos setores da sociedade que se encontram em situação de mais vulnerabilidade, como os grupos citados neste trabalho. Assim, é necessário demonstrar o compromisso do governo em seguir tanto a regra constitucional como os acordos internacionais firmados. Nesta mesma linha, considera-se de alta relevância que o país procure construir seus marcos regulatórios no sentido de alinhar-se aos pressupostos da DUBDH, tendo em vista que esta declaração apresenta valiosos princípios que devem ser considerados.

No comparativo apresentado, constatou-se que as mudanças que o projeto pretende auferir na lei não estão em consonância com os dispositivos conceituais que norteiam a BI, pois, em seus postulados, esta defende a proteção social e do meio ambiente como elementos básicos para empoderar populações, proporcionando-lhes autonomia mínima sobre sua existência e tratamento digno em relação ao respeito de suas culturas e práticas tradicionais.

O artigo buscou demonstrar que, se aprovado, o PL n. 827/2015 significará um retrocesso na proteção social e do meio ambiente. Assim, torna-se necessária a criação de instrumentos legais adequados, para que se consiga assegurar o mínimo para uma vida digna, como a segurança alimentar. Isso porque se entende que uma regulação de qualidade, com resultados efetivos e participação social, é fundamental para o estabelecimento de uma democracia verdadeiramente forte e equitativa.

\section{Referências}

AMORIM NETO, Otávio; SANTOS, Fabiano. O segredo ineficiente revisto: o que propõem e o que aprovam os deputados brasileiros. DADOS -- Revista de Ciências Sociais, Brasil, v. 46, n. 4, p. 661-698, 2003. Disponível em: <http://www.scielo.br/scielo.php?pid=S0011$52582003000400002 \&$ script $=$ sci_abstract\&tlng=es $>$. Acesso em: 28 set. 2016. http:// dx.doi.org/10.1590/S0011-52582003000400002.

ARANTES, Olívia Márcia Nagy. A bioética e a segurança alimentar: alimentos geneticamente modificados. Revista Brasileira de Pesquisa em Saúde, v. 14, n. 3, p. 14-20, 2012. Disponível em: <http://periodicos.ufes.br/RBPS/article/viewFile/4598/3567>. Acesso em: 20 de set. 2016. http://dx.doi.org/10.21722/rbps.v14i3.4598. 
ARAÚJO, J.C. A lei de proteção de Cultivares: análise de sua formulação e conteúdo. 1. ed. Brasília: Edições Câmara, 2010. (Série memória e análise de leis).

CARLINI-GARCIA, Luciana; PINTO, Luciana Rossini; LANDELL, Marcos Guimarães. Importância da manutenção de variabilidade genética para os produtores rurais. Secretaria de Agricultura de São Paulo, jul./dez. 2013. Disponível em: <http://www.aptaregional.sp.gov. br/acesse-os-artigos-pesquisa-e-tecnologia/edicao-2013/julho-dezembro-1/1444importancia-da-manutencao-de-variabilidade-genetica-para-os-produtores-rurais/ file.html>. Acesso em: 15 set. 2016.

CARSON, R. Primavera silenciosa. 1. ed. São Paulo: Ed. Gaia, 2012.

DINIZ, Eli. Uma perspectiva analítica para a reforma do Estado. Lua Nova, São Paulo, n. 45 , p. 29-48, 1998. Disponível em: <http://www.scielo.br/scielo.php?script=sci issuetoc\&pid=0102-644519980003\&nrm=iso\&lng=pt $>$. Acesso em 20 set. $2016 . \mathrm{http}: / /$ dx.doi.org/10.1590/S0102-64451998000300003.

EMBRAPA. EMPRESA BRASILEIRA DE PESQUISA AGROPECUÁRIA. A variabilidade genética como fator fundamental aos programas de melhoramento vegetal. Documentos online 29, 2002. Disponível em: <www.cnpt.embrapa.br/biblio/p_do29_5.htm>. Acesso em: 21 set. 2016.

Da bioética de princípios a uma bioética interventiva. Bioética, v. 12, n. 1, p. 125-134, 2005. Disponível em: <http://www.revistabioetica.cfm.org.br/index.php/ revista_bioetica/article/view/97/102>. Acesso em: 24 ago. 2016.

GARRAFA, Volnei. Inclusão social no contexto político da Bioética. Revista Brasileira de Bioética, v. 1, n. 2, p. 122-132, 2005. Disponível em: <http://bioetica.org/cuadernos/ bibliografia/garrafa.pdf $>$.

; PORTO, Dora. Intervention bioethics: a proposal for peripheral countries in a context of power and injustice. Bioethics, v. 17, n. 5-6, p. 399-416, 2003. Disponível em: <http:// onlinelibrary.wiley.com/doi/10.1111/1467-8519.00356/full >. Acesso em: 20 ago. 2016. http://dx.doi.org/10.1111/1467-8519.00356.

JUNGES, José Roque. A proteção do meio ambiente na Declaração Universal sobre Bioética e Direitos Humanos. Revista Brasileira de Bioética, v. 2, n. 1, p. 21-38, 2006.

KINZO, Maria D’Alva. A democratização brasileira: um balanço do processo político desde a transição. Perspectiva, São Paulo, v. 15, n. 4, p. 3-12, 2001. Disponível em: <http://www. scielo.br/scielo.php?script=sci_arttext\&pid=S0102-88392001000400002 >. Acesso em: 24 set. 2016. http://dx.doi.org/10.1590/S0102-88392001000400002.

LEITE, Débora Silva; MUNHOZ, Letícia Leite. Biotecnologia e melhoramento das variedades vegetais. Veredas do Direito: direito ambiental e desenvolvimento sustentável, Belo Horizonte, v. 10, n. 19, p. 23-44, jan./jun. 2013. Disponível em <http://www.domhelder.edu.br/revista/ index.php/veredas/article/view/301/337>. Acesso em: 11 ago. 2016. 
LEMOS, Leany Barreiro de S. O Congresso brasileiro e a distribuição de benefícios sociais no período 1988-1994: uma análise distributivista. DADOS - Revista de Ciências Sociais, v. 44, n. 3, p. 561-605, 2001. Disponível em: <http://www.scielo.br/pdf/dados/v44n3/a04v44n3. pdf> . Acesso em: 11 ago. 2016. http://dx.doi.org/10.1590/S0011-52582001000300004.

LEOPOLD, A. A Sand County Almanac. 1. ed. New York: Oxford University Press, 1949.

MINARÉ, Reginaldo. TIRFAA e o acesso ao patrimônio genético e repartição de benefícios. Audiência Pública da Câmara dos Deputados, 2013, Brasília. Disponível em: <http://www2. camara.leg.br/atividade-legislativa/comissoes/comissoes-permanentes/capadr/ audiencias-publicas/audiencias-publicas-2013/audiencia-publica-03-de-abril-de2013-cna>. Acesso em: 20 ago. 2016.

NASCIMENTO, Wanderson Flor; GARRAFA, Volnei. Por uma vida não colonizada: diálogo entre bioética de intervenção e colonialidade. Saúde e Sociedade, São Paulo, v. 20, n. 2, p. 287-299, 2011. Disponível em: <http://www.revistas.usp.br/sausoc/article/ download/29791/31673>. Acesso em: 5 nov. 2016. http://dx.doi.org/10.1590/S010412902011000200003.

PELWING, Andrea Becker; FRANK, Lúcia Brandão; BARROS, Ingrid Bergman. Sementes crioulas: o estado da arte no Rio Grande do Sul. Revista de Economia e Sociologia Rural, v. 46, n. 2, p. 391-420, 2008. Disponível em: <http://www.scielo.br/pdf/resr/v46n2/v46n2a05. pdf> . Acesso em: 17 ago. 2016. http://dx.doi.org/10.1590/S0103-20032008000200005.

PIPOLO, Antônio Eduardo; ARIAS, Carlos Alberto Arrabal; CARNEIRO, Geraldo Estevam de Souza; TOLEDO, José Francisco Ferraz. Desenvolvimento de Germoplasma e Cultivares de Soja. Circular Técnica n. 52. Empresa Brasileira de Pesquisa Agropecuária, set. 2007. Disponível em: $<$ https://www.infoteca.cnptia.embrapa.br/handle/doc/470314>. Acesso em: 25 ago. 2016.

POTTER, V.R. Bioética: ponte para o futuro. 1. ed. São Paulo: Ed Loyola; Sociedade Brasileira de Bioética, 2016.

SANTILLI, Juliana Ferraz da Rocha. Agrobiodiversidade e direitos dos agricultores. 2009. Tese (Doutorado) - Faculdade de Direito, Pontifícia Universidade Católica do Paraná, 2009.

SANTILLI, Juliana Ferraz da Rocha. Agrobiodiversidade e direito dos agricultores. 1. ed. São Paulo: Ed. Peirópoles, 2009.

A bioética como mecanismo de proteção dos conhecimentos tradicionais dos povos indígenas e de afirmação dos direitos humanos. Revista Direito em Debate - Revista do Departamento de Ciências Jurídicas e Sociais da Unijuí, v. 23, n. 42, p. 3-26, 2014. Disponível em: <https://www.revistas.unijui.edu.br/index.php/revistadireitoemdebate/ article/view/2984/3504>. Acesso em: 5 set. 2016. http://dx.doi.org/10.21527/21766622.2014.42.3-26.

SARAIVA, Alessandra. 7,2 milhões de pessoas passam fome no Brasil, mostra IBGE. Valor Econômico, 18 dez. 2014. Disponível em: <http://www.valor.com.br/brasil/3829144/72milhoes-de-pessoas-passam-fome-no-brasil-mostra-ibge>. Acesso em: 5 set. 2016. 
SELLI, Lucilda; GARRAFA, Volnei. Solidariedade crítica e voluntariado orgânico: outra possibilidade de intervenção societária. História, Ciências e Saúde - Manguinhos, v. 13, n. 2, p. 239-251, abr./jun. 2006. Disponível em <http://www.scielo.br/scielo.php?script=sci_ar ttext\&pid=S0104-59702006000200003 >. Acesso em: 5 nov. 2016. http://dx.doi. org/10.1590/S0104-59702006000200003.

SEVERINO, Mariana Rocha Souza; LIMA, Thaizi Leal Mesquita; LIMA, Gabriel Maciel; DANTAS, Tomas Kefas de Souza. A importância socioeconômica das cultivares para o desenvolvimento dos biocombustíveis no Brasil. In: SIMPÓSIO INTERNACIONAL DE INOVAÇÃO TECNOLÓGICA, v. 2, n. 1, p. 77-84, set. 2014. Disponível em: <http://www. portalmites.com.br/conferences/index.php/ISTI/isti2014/paper/download/25/12>. Acesso em: 20 ago. 2016. http://dx.doi.org/10.7198/S2318-3403201400020010.

VALOIS, Afonso Celso Candeira. Biotecnologia, biodiversidade e propriedade intelectual. Cadernos de Ciência e Tecnologia, Brasília, v. 15, esp. p. 21-31, 1998. Disponível em: <http:// www.egov.ufsc.br/portal/sites/default/files/anexos/27615-27625-1-PB.pdf>.

VIEIRA, Ana Beatriz Duarte; MONTEIRO, Pedro Sadi. Comunidade quilombola: análise do problema persistente do acesso à saúde, sob o enfoque da Bioética de Intervenção. Revista Saúde em Debate, Rio de Janeiro, v. 37, n. 99, p. 610-618, 2013. Disponível em: <http:// www.scielo.br/pdf/sdeb/v37n99/a08v37n99.pdf >. Acesso em: 17 ago. 2016. http://dx.doi. org/10.1590/S0103-11042013000400008.

Isabela Bonfim - Graduada em Ciência Política pelo Centro Universitário do Distrito Federal; Programa de Pós-Graduação em Bioética/Cátedra Unesco de Bioética da Universidade de Brasília. Brasília/DF, Brasil. E-mail: ibela.bonfim@gmail.com

Pedro Gomes - Graduado em Ciência Política pela Universidade de Brasília; Programa de Pós-Graduação em Bioética/Cátedra Unesco de Bioética da Universidade de Brasília. Brasília/ DF, Brasil.E-mail: pedro.gomes.01@gmail.com

Christiane Haidar - Graduada em Biologia pelo Centro Universitário de Brasília; Programa de Pós-Graduação em Bioética/Cátedra Unesco de Bioética da Universidade de Brasília. Brasília/DF, Brasil. E-mail: christiane.haidar@gmail.com

Volnei Garrafa - Pós-Doutor em Bioética. Membro do Comitê Internacional de Bioética da Unesco/Paris. Coordenador do Programa de Pós-Graduação em Bioética/Cátedra Unesco de Bioética da Universidade de Brasília. Brasília, Distrito Federal, Brasil. 